\title{
Experimental investigation of performance of a single phase UPQC for voltage sensitive and non-linear loads
}

\author{
Malabika Basu \\ Technological University Dublin, mbasu@tudublin.ie
}

S. P. Das

Jadavpur University

Gopal K. Dubey

Jadavpur University

Follow this and additional works at: https://arrow.tudublin.ie/engscheleart

Part of the Electrical and Computer Engineering Commons

\section{Recommended Citation}

Basu, Malabika and Das, S. P. and Dubey, Gopal K.: Experimental investigation of performance of a single phase UPQC for voltage sensitive and non-linear loads. Proceedings the 4th IEEE International Conference on Power Electronics and Drive Systems, 2001, Bali, 22-25 October, 2001, vol.1, pp. 218-222. doi:10.21427/fbkk-5659

This Conference Paper is brought to you for free and open access by the School of Electrical and Electronic Engineering at ARROW@TU Dublin. It has been accepted for inclusion in Conference papers by an authorized administrator of ARROW@TU Dublin. For more information, please contact arrow.admin@tudublin.ie, aisling.coyne@tudublin.ie,gerard.connolly@tudublin.ie. Funder: Department of Science and Technology, 


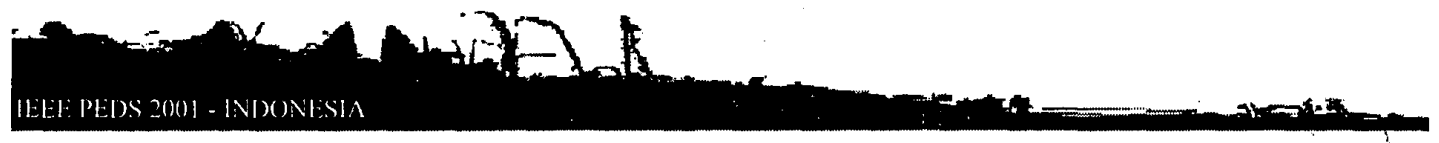

\title{
Experimental Investigation of Performance of a Single Phase UPQC for Voltage Sensitive and Non-linear Loads
}

\author{
Malabika Basu, S. P. Das, Member, IEEE, Gopal K. Dubey, Senior Member, IEEE
}

\begin{abstract}
A Unified Power Quality Conditioner (UPQC) is proposed in this paper. It protects the consumer at the load end from supply voltage sag, and provides unity power factor condition at the utility for different values of load power factor. A PC-based closed loop control scheme is proposed and experimental investigation is carried out in the laboratory. Selected experimental results are reported along with control circuit and phasor diagram to validate the proposition.
\end{abstract}

Index Terms-Harmonic current elimination, hybrid control, power factor correction, voltage sag

\section{INTRODUCTION}

DOWER line disturbances can often lead to severe loss in automated production industries, where sophisticated process controllers, such as PLCs, industrial control relays and contactors, solenoids and other protection devices trip due to voltage sag. Further, the adjustable speed drives, switching power supplies and industrial illumination are also affected by short duration voltage sag [1]. In paper and textile mills, speed fluctuation in the drives due to short-term voltage sag can cause large production losses. According to the power quality survey reports [2], [3], 68\% of the disturbances are short duration shallow voltage sags (typically $15 \%$ sag for a few cycles), which cost billions of dollars in production loss per year [3], [5].

Therefore, such consumers are keen to keep their load end voltages insensitive to the supply voltage sags at the cost of additional expenditure for ultimately greater profits. This motivation has given a thrust to investigate a power conditioning equipment for voltage sensitive loads. Combining a series voltage compensator with a synchronous link converter VAR compensator (SLCVC) [6], a multipurpose

This work was supported by Department of Science and Technology, Govt. of Inida.

Malabika Basu is with the Department of Electrical Engineering, Jadavpur University, Calcutta-32,India (e-mail: bbasul@vsnl.com)

S. P. Das is with the Department of Electrical Engineering, Indian Institute of Technology, Kanpur, India (e-mail: spdas@iitk.ac.in).

Gopal K. Dubey is with the Department of Electrical Engineering, Indian Institute of Technology, Kanpur, India (e-mail: gdubey@iitk.ac.in). power conditioning equipment is proposed in this paper having the following facilities.

1. The Unified Power Quality Conditioner (UPQC) maintains load end voltage at the rated value, in case of sudden supply voltage sag.

2. It eliminates the harmonics in the supply current, thus improves the utility current quality for nonlinear loads.

3. It provides the VAR requirement of the load, so that the supply voltage and current are always in phase, therefore, no additional power factor correction equipment is necessary.

4. The present scheme does not use any separate diode bridge rectifier to support the dc link voltage for the series compensator, and does not inject any harmonics in the supply current. The synchronous link converter maintains the common dc link voltage.

The voltage to be boosted in case of sag is always in quadrature advance to the supply voltage. The quadrature injection of voltage requires additional capacity of series compensator and puts limitation on the range of sag mitigation. However, this scheme leads to a reduced VA rating of the shunt compensator as active power consumption by the series compensator is minimized. Additionally, the series compensator shares a part of VAR of the load.

The schematic diagram, control block diagram and typical experimental results are provided to show the effectiveness of the scheme.

\section{CONFIGURATION OF THE PROPOSED UPQC}

The schematic diagram of the proposed UPQC is shown in Fig. 1. The UPQC consists of two single-phase inverters connected in cascade in such a manner that the inverter-II (synchronous link converter VAR compensator (SLCVC)) is connected in parallel to the load. The inverter-I (series compensator) is connected in series with the supply voltage through a coupling transformer. The main objectives of the SLCVC are to compensate for the reactive power demanded by the load, to eliminate the harmonics from the supply 


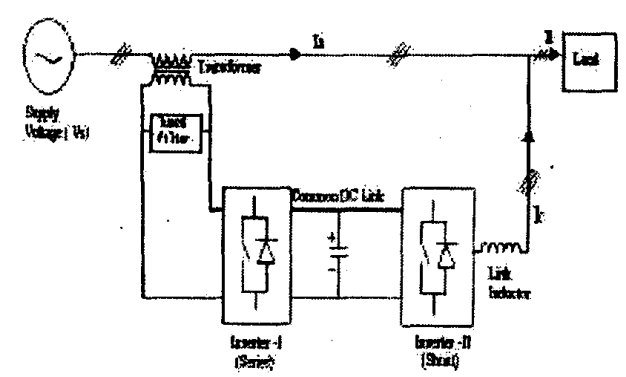

Fig.l Schematic diagram of UPQC

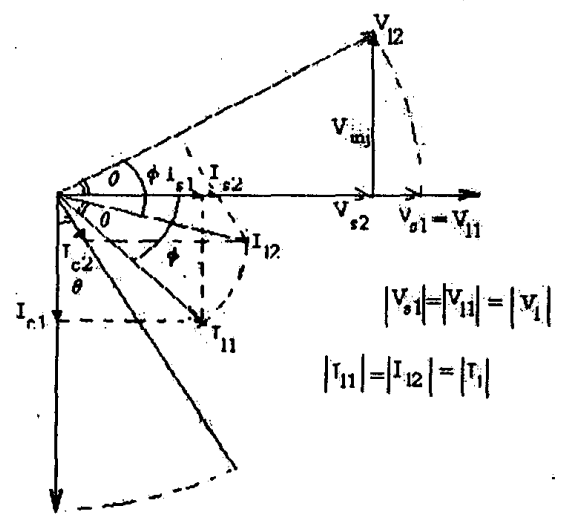

Fig.2 Phasor diagram of the UPQC

current and to regulate the common dc link voltage. The SLCVC operates with hysteresis current controlled mode to make the supply current in phase with the supply voltage

The series compensator operates in a PWM voltage controlled mode. It injects voltage in quadrature advance to the supply voltage (current) such that the load end voltage is always maintained at the desired value. The two inverters operate in a coordinated manner.

The phasor diagram of Fig. 2 explains the operation of the UPQC. When the supply voltage, $V_{s 1}$, is at the rated value, the load voltage $V_{1}\left(\left|V_{1}\right|=\left|V_{11}\right|=\left|V_{s}\right|\right)$ is also at the rated level. The load current is $I_{11}\left(\left|I_{11}\right|=\left|I_{1}\right|\right)$ and the SLCVC compensates the reactive component $I_{c \mid}$ of load resulting in unity power factor, hence the load appears to draw only in-phase component $I_{s !}$ from the supply.

Now, if there is a sag in the supply, such that the supply voltage falls to $V_{s 2}\left(\left|V_{s 2}\right|<\left|V_{s 1}\right|\right)$, the series compensator injects a voltage, $V_{i n j}$, such that the magnitude of the resultant voltage at the load end $\left(V_{12}\right)$ is maintained at $\left|V_{1}\right|$. The load current changes to $I_{12}$. Now the shunt inverter injects $I_{c 2}$ in such a fashion that the utility current is $I_{s 2}\left(I_{s 2}=I_{12}(\cos \varphi / \cos \theta)\right)$ (keeping the power balance of the whole system), which is in phase with the supply voltage. Between the control loops, the analog hysteresis current control loop used with the SLCVC is much faster than the voltage control loop of the series converter. For non-linear loads, harmonic elimination and VAR compensation are first done by the shunt compensator, so the utility sees the load to be always linear and of u.p.f. A slower digital controller simultaneously corrects the voltage sag. The series voltage compensator always sees the supply current to be in phase with the voltage due to the faster compensation by the shunt controller. The two loop speeds are chosen such that in no case these two controllers can interfere with each other and cause instability.

\section{CONTROL STRATEGY}

Fig. 3 shows the block diagram of the controller used for the UPQC. $V_{d c}{ }^{*}$ (reference dc link voltage) is selected depending upon the maximum VAR to be compensated and the percentage sag to be mitigated. The error in the dc link voltage $\left(\mathrm{V}_{\mathrm{dc}}{ }^{*}-\mathrm{V}_{\mathrm{dc}}\right)$ gives a direct measure of active power requirement of both load and UPQC from the supply.

To enhance the speed of response and also to retain the flexibility to modify parameters of the controller, a new hybrid type of controller has been proposed. Here the dc link voltage control is completely controlled by a PC-based software. After the dc link voltage is sensed, it is compared inside the $\mathrm{PC}$ with the reference dc link voltage and the error is processed through a software PI controller. The output of the PI controller is multiplied by the sinusoidal template, which is in phase with the supply voltage, to produce the reference current for the supply. To keep the current within a hysteresis band, an analog hysteresis comparator is implemented for fast and accurate control of current, bypassing the limitation of speed of data acquisition cards. Thus the hybrid control method maintains the accuracy, speed and flexibility, combining the advantages of analog and digital controllers.

For the series compensator, the supply voltage peak and an appropriate sinusoidal template for quadrature advance injection are sensed through AD channels, and a feed-forward loop is used to calculate the modulating signal. The actual voltage injected is also sensed through the ADC and is compared in the PC with the reference injected voltage. The error is processed through a PI controller, which acts as a feedback loop. This takes care of the dynamics of any incremental change in phase angle that may occur due to load current variation.

When a sag is detected such that $\left|V_{s 2}\right|\left\langle\left|V_{s 1}\right|\right.$ (rated), $V_{i n j}=$ $\sqrt{ }\left(\mathrm{V}_{\mathrm{s} 1}{ }^{2}-\mathrm{V}_{\mathrm{s} 2}{ }^{2}\right)$

From PWM method [4],

$\sqrt{2} V_{i n j}=m\left(V_{d c} / 2\right)$, where $m$ is the modulating index (MI).

Therefore, $\mathrm{m}=\left(2 \sqrt{2} \cdot \mathrm{V}_{\mathrm{inj}}\right) / \mathrm{V}_{\mathrm{dc}}$

And if $x$ is the p.u. sag to be mitigated, minimum de link voltage, $\mathrm{V}_{\mathrm{dc}}=2 \sqrt{2} \cdot \sqrt{x(2-x)} \cdot \mathrm{V}_{\mathrm{s} 1}$, for maximum $\mathrm{MI}=\mathrm{I}^{\prime}$

(taking the series transformer turns ratio to be 1:1). 


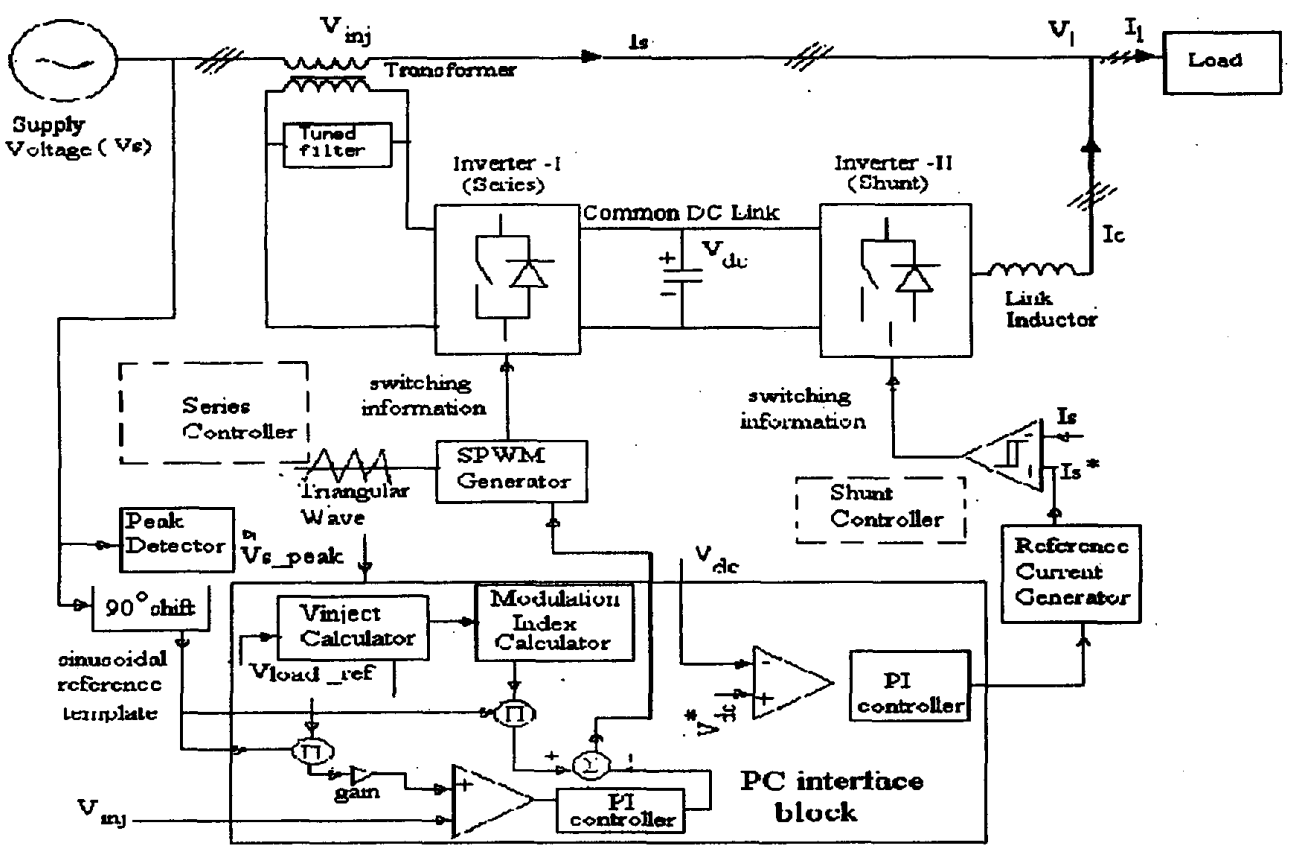

Fig.3 Control block diagram of a single phase UPQC

\section{Possible Modes of Power Flow}

The control strategy is such that the series inverter injects voltage in quadrature to the supply voltage, and so the flow of active power is directly from supply to load. But the reactive power flow to the load may be shared by both the converters, as the series converter also plays the role of a VAR generator. As a result, the burden of supplying VAR to load reduces on the (parallel) shunt converter and its VA rating gets reduced.

\section{RESULTS AND DISCUSSIONS}

To validate the proposition, extensive simulation has been carried out and a prototype laboratory setup has been developed.

The UPQC is made of two single phase full bridge inverters, with the help of dual IGBT module having rating of $1200 \mathrm{~V}, 50 \mathrm{~A}$. The dc link capacitor is $2200 \mu \mathrm{F}, 400 \mathrm{~V}$ dc. The value of the synchronous link inductor is $4.5 \mathrm{mH}$. For laboratory purpose, a 2:1 transformer of $220 \mathrm{~V} / 110 \mathrm{~V}, 1$ kVA is used at the output of the series inverter to inject the voltage in series with the supply. The PWM voltage of the series inverter is filtered through a low pass filter of $L=4.3$ $\mathrm{mH}$ and $\mathrm{C}=60 \mu \mathrm{F}$. The supply voltage has been taken as $40 \mathrm{~V} \mathrm{rms}$, and reference dc link voltage is $100 \mathrm{~V}$.
The load is a diode bridge rectifier, which has an R-L load at its dc side. A load current change from $1.8 \mathrm{~A}$ to 2.5 $A$ is performed to observe the transient performance of the UPQC for step load variation.

Another load, which is capable of drawing relatively much larger current, is connected in parallel with the supply. to introduce a supply voltage sag due to voltage drop in the internal impedance. When this large load is switched on, the supply voltage dips and a voltage dip is also observed at the load end. During this phenomenon, the performance of the UPQC to maintain the load end voltage to its desired value is observed.

Some typical experimental results (Fig. 4 to Fig. 10) are reported here.

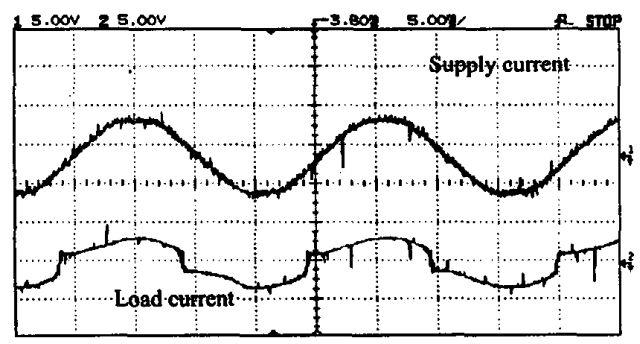

Fig. 4 Supply current and load current at steady state 


\section{A. Steady State Performance}

Fig. 4 shows supply current and the load current for a non-linear load. It can be seen that with the UPQC, the supply current is sinusoidal when the load current contains harmonics. The supply current and reference current waveforms (which are in phase with the supply voltage) are given in Fig. 5.

Fig. 6 shows the load current harmonic spectrum, where the low order harmonics $\left(3^{\text {rd }}, 5^{\text {th }}, 7^{\text {th }}, 9^{\text {th }}, 11^{\text {th }}, 13^{\text {th }}\right.$, and

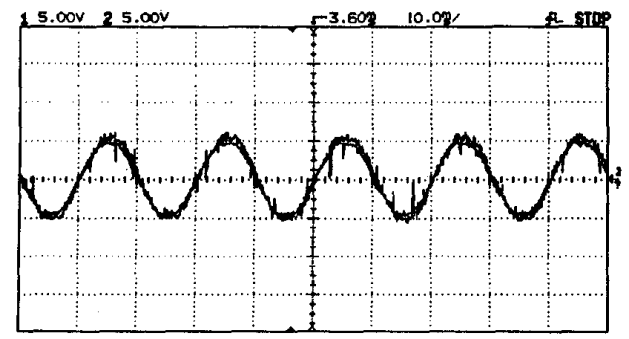

Fig. 5 Reference supply current and actual supply current

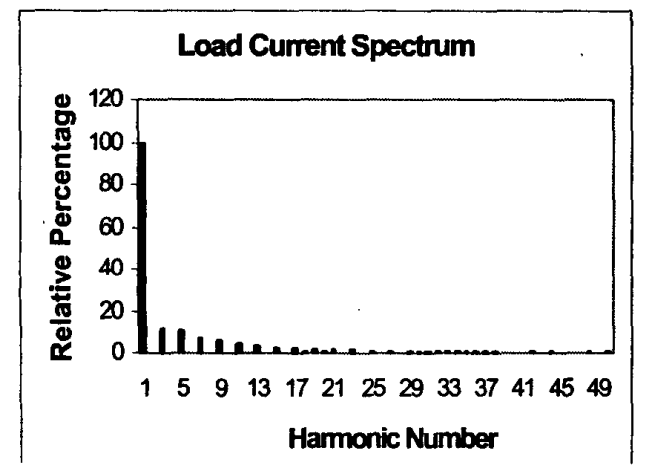

Fig.6 Harmonic spectrum of diode bridge rectifier input current

$17^{\text {th }}$ ) are quite significant and the total harmonic

Distortion (THD) is $14.6 \%$. Fig. 7 shows the supply current harmonic spectrum after effective active filtering. The load current harmonics are compensated by the shunt active filter of the UPQC and so the utility is spared from unwanted load current harmonics.

The actual current follows the reference current within an appropriate hysteresis band. The measured THD is $3.75 \%$, which is well within permissible limit of $5 \%$ as recpmmended by IEEE-519. Fig. 8 shows the load and supply voltage waveforms. The Trace- 3 shows the actual injected voltage in a scaled down form with a multiplication factor of 38 . The measured THD of the load voltage after series compensation for a $14.8 \%$ sag is $3.5 \%$. The injected voltage is in quadrature advance with respect to the supply voltage, as seen in the figure.

.B. Transient Performance of UPQC

Following results demonstrate the transient response of the UPQC under (a) load change, (b) transient voltage sag.

\section{Load Change}

When there is a sudden load change from $1.8 \mathrm{~A}$ to $2.5 \mathrm{~A}$ as shown in Fig. 9, the supply current increases adequately to cater the additional active power. However, in all conditions the supply current is sinusoidal and remains in phase with supply voltage.

Fig.10 shows the effect of load change on the dc link voltage. The dc link voltage dip is around $2 \mathrm{~V}$, which regains its reference value soon due to the effect of closed loop control.

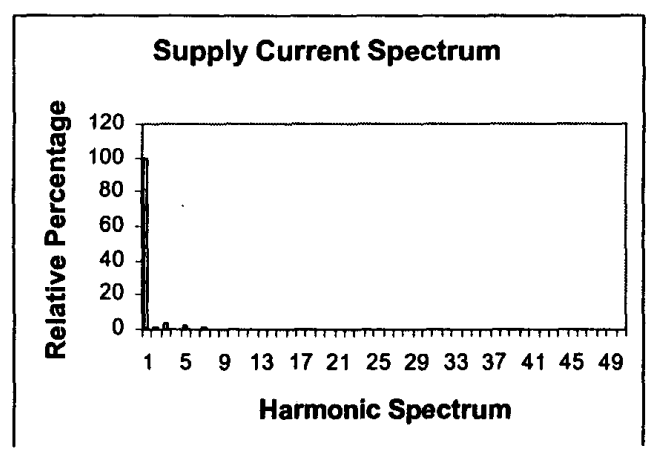

Fig. 7. Supply current harmonic spectrum

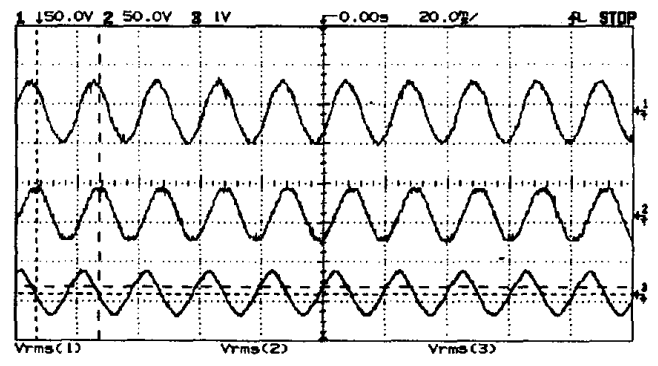

Fig. 8 Different voltage waveform

Trace 1 Load voltage

Trace 2 Supply voltage

Trace 3 Series injected voltage/38.

\section{Transient voltage sag}

Fig. 11 demonstrates the effective operation of the series converter control. Due to the series converter closed loop 


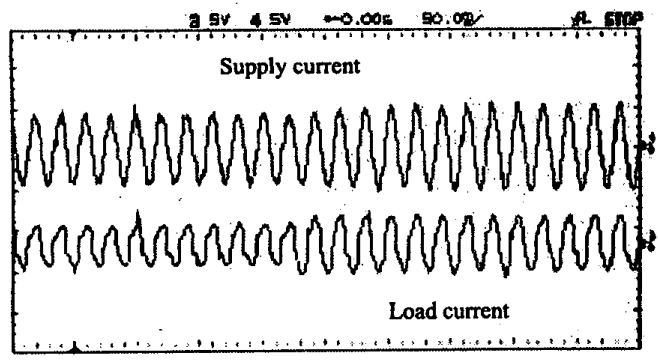

Fig. 9. Transient load change from 1.8 A To $2.5 \mathrm{~A}$

control, the load voltage is maintained at its specified value. Trace 2 shows the actual voltage injected to the supply from the series inverter.

The pointer in Fig. 11 indicates the instant of the change in injected voltage, which takes place according to the supply voltage support requirement. The injected voltage reduces to a very nominal value after the $14.8 \%$ sag in supply voltage is regained.

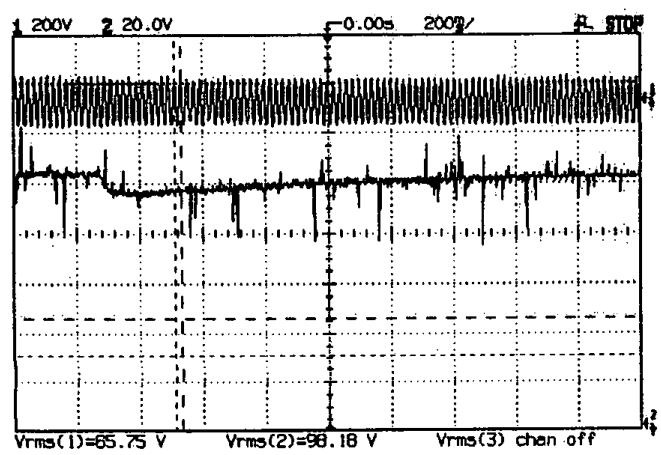

Fig. 10 Trace 1 load voltage Trace 2 DC link voltage due to a transient load change

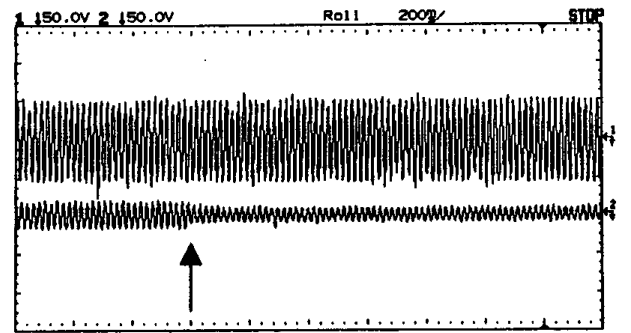

Fig.11 Injected voltage is adjusted according to supply requirement

\section{CONCLUSION}

A UPQC for voltage sag correction and load harmonic current and VAR compensation has been discussed.

The UPQC does not require external dc link voltage support from any source, so it can compensate for voltage sag for any amount of time.

The implementation of the hybrid control scheme resulted in fast and accurate hysteresis control of the supply current, flexible parameter control of the digital PI controller, and fast dynamic response with reasonably low sampling frequency. The control scheme is experimentally validated and typical transient and steady state results are presented.

As the series inverter fo the UPQC is also capable of delivering VAR to the load, the rating of the shunt inverter can be lowered.

The results show good performance of the UPQC with non-linear load and supply voltage sag.

\section{ACKNOWLEDGMENT}

The authors would like to thank the Department of Science and Technology (DST), Govt. of India for sponsoring the project.

\section{REFERENCES}

[1] M. F. McGranaghan, D.R. Mueller, and M. J. Samotyj, "Voltage ags in industrial systems," IEEE Trans. Ind. Applications. Vol. 29, no.2, pp.397-402, March/April 1993

[2] H. G. Sermiento and E. Estrada, "A voltage sag study in an industry with adjustable speed drives," IEEE Ind. Applicat. Mag., Vol. 2, pp. 16-19, Jan/Feb 1996.

[3] V. E. Wagner, A. A. Andershak, and J. P. Staniak, "Power quality and factory automation," IEEE Trans. Ind. Applications. Vol. 26, pp. 620-626, July/August 1990.

[4] N. Mohan, T. M. Undeland, Power Electronics:Converters, Application and Design. New York: Wiley, 1989.

[5] Serge Bernard, "Harmonics Pollution," available at http://www powerquality.com/arc/art/harmonics, html.

[6] K. Chatterjee, B.G. Fernandes, and G.K. Dubey, "An instantaneous reactive Volt-Ampere compensator and harmonic suppressor system," IEEE Trans. Power Electronics Vol. 14, no. 2, pp. 381 392, March 1999. 